\title{
BMJ
}

\section{Inequity of access to investigation and effect on clinical outcomes: prognostic study of coronary angiography for suspected stable angina pectoris}

\author{
Neha Sekhri, clinical research fellow, ${ }^{1}$ Adam Timmis, professor of clinical cardiology, ${ }^{1}$ Ruoling Chen, senior \\ lecturer in epidemiology, ${ }^{2}$ Cornelia Junghans, research fellow in epidemiology, ${ }^{2}$ Niamh Walsh, statistician, ${ }^{3}$ \\ Justin Zaman, clinical research fellow in epidemiology, ${ }^{2}$ Sandra Eldridge, professor of biostatistics, ${ }^{3}$ \\ Harry Hemingway, professor of clinical epidemiology, ${ }^{2}$ Gene Feder, professor of primary health care ${ }^{4}$
}

\begin{abstract}
${ }^{1}$ Cardiac Directorate, Barts and the London NHS Trust, London

${ }^{2}$ Department of Epidemiology and Public Health, University College London Medical School, London

${ }^{3}$ Centre for Health Sciences, Barts and the London, Queen Mary's

School of Medicine and Dentistry, Queen Mary, University of

London, London

${ }^{4}$ Academic Unit of Primary Health Care, University of Bristol, Bristol BS8 2AA

Correspondence to: $\mathrm{G}$ Feder gene.feder@bristol.ac.uk
\end{abstract}

doi:10.1136/bmj.39534.571042.BE

\section{ABSTRACT}

Objectives To determine whether coronary angiography for suspected stable angina pectoris is underused in older patients, women, south Asian patients, and those from socioeconomically deprived areas, and, if it is, whether this is associated with higher coronary event rates. Design Multicentre cohort with five year follow-up. Setting Six ambulatory care clinics in England.

Participants 1375 consecutive patients in whom coronary angiography was individually rated as appropriate with the Rand consensus method.

Main outcome measures Receipt of angiography (420 procedures); coronary mortality and acute coronary syndrome events.

Results In a multivariable analysis, angiography was less likely to be performed in patients aged over 64 compared with those aged under 50 (hazard ratio 0.60, 95\% confidence interval 0.38 to 0.96 ), women compared with men $(0.42,0.35$ to 0.50$)$, south Asians compared with white people $(0.48,0.34$ to 0.67$)$, and patients in the most deprived fifth compared with the other four fifths ( 0.66 , 0.40 to 1.08 ). Not undergoing angiography when it was deemed appropriate was associated with higher rates of coronary event.

Conclusions At an early stage after presentation with suspected angina, coronary angiography is underused in older people, women, south Asians, and people from deprived areas. Not receiving appropriate angiography was associated with a higher risk of coronary events in all groups. Interventions based on clinical guidance that supports individualised management decisions might improve access and outcomes.

\section{INTRODUCTION}

We do not know whether potential inequities in the management of cardiovascular disease have consequences in terms of prognosis. Equitable access to health care is a widely accepted goal for health services internationally and a key principle of the NHS. ${ }^{1} \mathrm{Most}^{2-4}$ but not all ${ }^{56}$ studies suggest that older people, ${ }^{7}$ women, ${ }^{8}$ ethnic minorities, ${ }^{9}$ and those who are socioeconomically deprived ${ }^{10}$ have less access to effective interventions for stable angina or acute coronary events.

There are still important uncertainties that hamper the transition from "talk" about inequitable access to "action" and the development of policies to reduce inequities. ${ }^{11}$ Firstly, in patients with stable angina investigators rarely measure the effect on cardiac events or mortality of variation in management. ${ }^{12}$ Prognostic studies of patients early in the course of chronic coronary disease are lacking. Secondly, most studies that have found inequitable access to services are based on patients with acute events ${ }^{13}$ or identified in hospital outpatient settings, ${ }^{14}$ although many presented years earlier in primary care. Few studies have identified patients at an early stage of presentation in the context of primary or ambulatory care. Thirdly, most studies have examined access to treatments. Yet investigations such as coronary angiography are a prerequisite for revascularisation and some decisions about medical management. Finally, most previous studies have not taken account of the appropriateness of coronary angiography ${ }^{15}$ or the confounding of comorbidity in decisions about investigations. We have previously shown that appropriateness criteria for revascularisation developed by the Rand-UCLA method predictedoutcomes in a cohort of 2552 patients presenting for angiography. ${ }^{16}$

We assessed patients in rapid access chest pain clinics who were deemed appropriate for coronary angiography to determine whether angiography was underused inpatients who were older, women, from a south Asian ethnic group, or from economically deprived areas; and whether underuse was associated with higher rates of coronary events. In the United Kingdom, most people identified in general practice with recent onset stable chest pain are assessed in rapid access chest pain clinics. These ambulatory care clinics are run by cardiology teams and accept same day referrals from family physicians of patients with recent onset chest 
pain who have not previously been investigated or diagnosed with coronary disease. ${ }^{17}$

We used a multicentre cohort of consecutive patients attending these clinics and independently assessed their appropriateness for angiography using criteria that we developed using the Rand-UCLA consensus method. ${ }^{16}$

\section{METHODS}

Data sources and definitions

Individual clinical data on 10634 consecutive people attending six rapid access chest pain clinics were electronically recorded from 2 January 1996 to 31 December 2002 on identical databases, details of which have been reported previously. ${ }^{18}$ An independent panel deemed 1375 of these patients as appropriate for angiography. Figure 1 shows the origins of the study sample. The study size was determined by the availability of systematically collected comprehensive baseline data in the six clinics using the same electronic record system. The clinics were sited in Blackburn, Burnley, Kingston, Manchester, Newham, and Oldchurch. Clinical data collected at attendance included age, sex, ethnicity, duration of symptoms, character of chest pain, smoking status, history of hypertension, diagnosis of diabetes, resting and exercise electrocardiograms (ECG), pulse rate, systolic blood pressure, drugs, and follow-up plan on discharge. At the end of the consultation the clinician recorded the cause of chest pain (angina or non-cardiac chest pain).

\section{Ethnicity}

During the consultation the clinician who assessed the patient in the clinic ascribed ethnicity as Asian, white, black, or other. "Asian" was used for patients of Indian, Pakistani, Sri Lankan, and Bangladeshi origin, and we have referred to this category as "south Asian" in this paper. In our analysis we compared white and south Asian patients. In the UK south Asian people are at particularly high risk of coronary artery disease. ${ }^{19} \mathrm{We}$ did not have the power to analyse differences in access and outcomes of other ethnic minority groups (African and Afro-Caribbean) because of their relatively low incidence of coronary disease and small numbers of patients in our cohort.

\section{Deprivation}

We used fifths of the 2001 census Townsend index, a score of material deprivation ${ }^{20}$ based on four variables (unemployment, overcrowding, car ownership, and home ownership). In our analysis we compared the most deprived (highest fifth) with the other four combined.

\section{Appropriateness ratings for angiography}

Before undertaking this study, we defined the appropriateness of angiography with two expert panels using a modification of the Rand/UCLA method of systematically combining evidence with expert opinion. ${ }^{21} \mathrm{We}$ identified 13 clinical descriptors that influence the decision to undertake angiography on people with

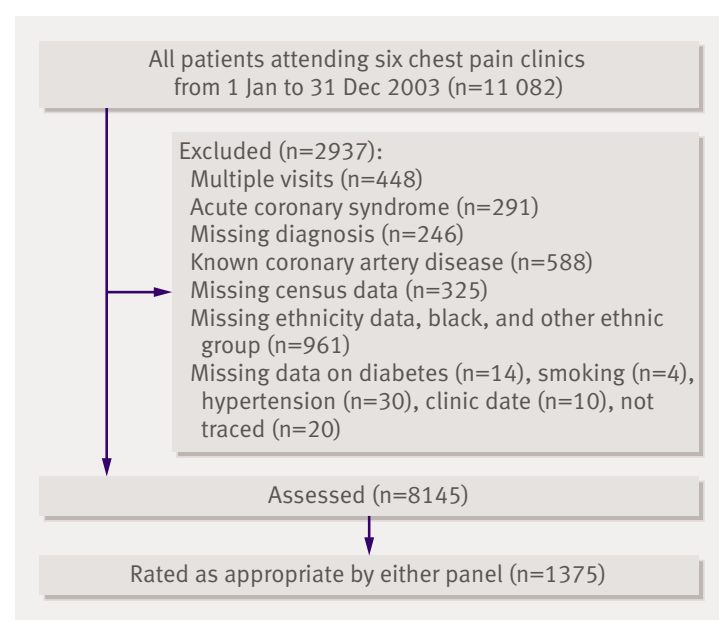

Fig 1 |Flow diagram of patients in cohort

suspected or confirmed angina: age $(<40,40-49,50-59$, 60-74, 75-84), sex, typicality of symptoms, severity of symptoms (Canadian Cardiovascular Society (CCS) class), drugs for symptoms (submaximal, maximal), coronary risk factors (low, medium, high), previous acute coronary syndrome, timing of acute coronary syndrome (within past year, more than a year ago), resting ECG (normal, abnormal), findings on exercise ECG (none, normal, abnormal, very abnormal), previous result of angiography, (abnormal, normal), timing of angiography (within past year, more than a year ago), previous revascularisation. We used clinically meaningful combinations of these factors to define specific clinical indications that we grouped in six broad clinical presentations.

Each panel consisted of five cardiologists, five family physicians, and one cardiothoracic surgeon. Panellists judged appropriateness for angiography on a 9point scale. Scores of 7-9 indicated an appropriate investigation, when benefit from subsequent treatment was judged to outweigh harm. Panellists were invited to base their ratings on evidence from peer reviewed research and were provided with a literature review with evidence tables and graded strength of evidence. ${ }^{22}$ They were asked to rate purely on the basis of clinical benefit and harm, without consideration of financial or workload constraints. Panel members carried out the first round of rating independently and then had the opportunity to change their ratings in the light of a panel discussion.

We matched indications and their associated ratings to patients from the six clinics, based on the 13 clinical individual clinical characteristics and initial investigations listed above, with the exception of CCS class. Patients were included in our analysis if either panel had deemed their indications appropriate for angiography.

\section{Sample population}

Our sample comprised white or south Asian patients with chest pain and no known coronary heart disease presenting to rapid access chest pain clinics and 
Table 1|Characteristics of 1375 patients deemed appropriate for coronary angiography. Figures are numbers (percentages) of patients unless stated otherwise

\begin{tabular}{|c|c|c|c|}
\hline Variables & $\begin{array}{l}\text { Received angiography } \\
(420,31 \%)\end{array}$ & $\begin{array}{c}\text { Did not receive } \\
\text { angiography }(955,69 \%)\end{array}$ & P value \\
\hline \multicolumn{4}{|l|}{ Age (years): } \\
\hline Mean (SD) & $61.0(8.9)$ & $62.3(8.6)$ & 0.014 \\
\hline$\leq 49$ years & $42(10)$ & $70(7)$ & \multirow{3}{*}{0.030} \\
\hline 50-64 years & 217 (52) & $452(47)$ & \\
\hline$\geq 65$ years & $161(38)$ & $433(45)$ & \\
\hline \multicolumn{4}{|l|}{ Sex: } \\
\hline Men & $270(64)$ & $360(38)$ & \multirow{2}{*}{$<0.001$} \\
\hline Women & $150(36)$ & $595(62)$ & \\
\hline \multicolumn{4}{|l|}{ Ethnicity: } \\
\hline White & $370(88)$ & $742(78)$ & \multirow{2}{*}{$<0.001$} \\
\hline South Asian & $50(12)$ & $213(22)$ & \\
\hline \multicolumn{4}{|l|}{ Deprivation (fifths): } \\
\hline Less deprived (1-4) & $360(86)$ & $727(76)$ & \multirow{2}{*}{$<0.001$} \\
\hline Most deprived (5) & 60 (14) & $228(24)$ & \\
\hline
\end{tabular}

Risk factors:

\begin{tabular}{|c|c|c|c|}
\hline Smoking: & & & \\
\hline Never smoked & 137 (33) & $236(25)$ & \multirow{3}{*}{$<0.001$} \\
\hline Ex-smoker & $184(44)$ & $533(56)$ & \\
\hline Current smoker & 99 (24) & 186 (19) & \\
\hline Diabetes & $52(12)$ & 130 (14) & 0.535 \\
\hline Hypertension & $187(45)$ & $431(45)$ & 0.835 \\
\hline $\begin{array}{l}\text { hean (SD) systolic blood pressure } \\
\mathrm{mm} \mathrm{Hg} \text { ) }\end{array}$ & $145.7(19.1)$ & $147.2(21.8)$ & 0.196 \\
\hline
\end{tabular}

Duration of chest pain:

\begin{tabular}{|c|c|c|c|}
\hline « weeks & $136(32)$ & 375 (39) & \\
\hline $1-\measuredangle 6$ months & $190(45)$ & $376(39)$ & 0.043 \\
\hline $6-<12$ months & 94 (22) & $204(21)$ & \\
\hline
\end{tabular}

Diagnosis:

\begin{tabular}{|c|c|c|c|}
\hline Angina & $413(98)$ & $786(84)$ & \multirow{2}{*}{$<0.001$} \\
\hline Non-cardiac pain & $7(2)$ & $149(16)$ & \\
\hline \multicolumn{4}{|c|}{ Result of exercise electrocardiography: } \\
\hline Positive & $316(75)$ & $414(43)$ & \multirow{4}{*}{$<0.001$} \\
\hline Negative & $12(3)$ & $143(15)$ & \\
\hline Non-diagnostic & $18(4)$ & $74(8)$ & \\
\hline Not done & $74(18)$ & $324(34)$ & \\
\hline
\end{tabular}

Outcome of clinic appointment*:

\begin{tabular}{|c|c|c|c|}
\hline Admitted & $0(0)$ & $3(0.3)$ & \multirow{4}{*}{$<0.001$} \\
\hline Outpatient appointment & $110(27)$ & $572(61)$ & \\
\hline Referred for angiography & $289(70)$ & $139(15)$ & \\
\hline Discharged back to GP & $16(4)$ & $223(24)$ & \\
\hline \multicolumn{4}{|l|}{ Drugs on discharge: } \\
\hline Aspirin & $367(87)$ & $722(76)$ & $<0.001$ \\
\hline$\beta$ blocker & $278(66)$ & $504(52)$ & $<0.001$ \\
\hline Statin & $130(31)$ & $250(26)$ & 0.068 \\
\hline \multicolumn{4}{|l|}{ Revascularisation: } \\
\hline $\begin{array}{l}\text { Percutaneous transluminal } \\
\text { angioplasty within } 3 \text { years }\end{array}$ & $56(13.3)$ & $32(3.4)$ & $<0.001$ \\
\hline $\begin{array}{l}\text { Coronary artery bypass graft within } \\
3 \text { years }\end{array}$ & $54(12.9)$ & $24(2.5)$ & $<0.001$ \\
\hline Any coronary revascularisation & $107(25.5)$ & $54(5.7)$ & $<0.001$ \\
\hline
\end{tabular}

*Data missing for 23 patients. chest pain; cardiac risk factors; results of resting and exercise ECGs) to the panels' ratings to define whether they were appropriate for coronary angiography.

\section{Missing baseline data}

In the total cohort of 10634 patients, 801 had incomplete baseline data (7.5\%). We did not include these patients in the main analysis; a sensitivity analysis showed that the rates of coronary deaths and non-fatal events for patients with angina and non-cardiac chest pain with missing baseline data were not significantly different from those with angina and non-cardiac chest pain and complete baseline data.

\section{Follow-up of patients and outcome measures}

Over $99 \%$ of patients were successfully matched at the Office for National Statistics and the NHS-wide clearing system who informed us of the date and ICD-10 (international classification of diseases, 10th revision) coded cause of death and hospital discharge, respectively. Average follow-up for the cohort was three years, until the end of 2003. Analysis of receipt of angiography was truncated three years after the index clinic visit. Data on use of coronary angiography were obtained from the NHS-wide clearing system. We analysed a single combined end point of death from coronary heart disease (ICD I20-I25) and admission to hospital because of acute coronary syndromes, including acute myocardial infarction (I21-I23) and unstable angina (I20.0-I20.9, I24.0, I24.8 and I24.9). We used the primary discharge diagnosis after hospital admission to define non-fatal events in these analyses. To define a group of patients without major comorbidity we identified those without any hospital admission for non-coronary reasons within a year of the clinic visit.

\section{Analysis}

We performed all analyses in STATA version 8 .

\section{Receipt of angiography}

We fitted univariate and multivariable Cox's regression models to estimate rates of receipt of angiography by age group, sex, ethnic group, and deprivation. The multivariable models included the clinic in which patients were assessed as a random variable. The proportional hazards assumption of the final Cox model was tested by calculating Schoenfeld residuals. We used severity of symptoms to define appropriateness ratings. As Canadian Cardiovascular Society (CCS) angina class was not recorded in this cohort, we assumed all patients were CCS class I-II (mild symptom severity). We chose this assumption because it would underestimate the need for angiography. In a further analysis we made the opposite assumption, coding the patients as class III-IV.

\section{Coronary events}

To measure the effect of underuse of angiography on morbidity and mortality in these demographic subgroups we fitted univariate and multivariable random effects Cox's regression models to estimate the hazard deemed appropriate for coronary angiography by either panel. We matched the patient's characteristics (age; typical, atypical, or non-cardiac symptoms of 
Table 2 Hazard ratios for receipt of angiography $(n=420)$ within three years of index clinic attendance of 1375 patients deemed appropriate for angiography

\begin{tabular}{|c|c|c|c|}
\hline \multirow[b]{2}{*}{ Variable } & \multirow{2}{*}{$\begin{array}{c}\text { No of procedures/No of } \\
\text { patients (\%) }\end{array}$} & \multicolumn{2}{|c|}{ Hazard ratio $(95 \% \mathrm{Cl})$, P value } \\
\hline & & Univariate & Multivariable* \\
\hline \multicolumn{4}{|l|}{ Age (years): } \\
\hline$\leq 49$ & $42 / 112(38)$ & $1 \dagger$ & $1 \dagger$ \\
\hline $50-64$ & $217 / 669(32)$ & $\begin{array}{c}0.82(0.70 \text { to } 113) \\
0.227\end{array}$ & 0.80 (0.64 to 1.01$), 0.058$ \\
\hline$\geq 65$ & $161 / 594(27)$ & $\begin{array}{c}0.66(0.42 \text { to } 1.06) \\
0.083\end{array}$ & 0.60 (0.38 to 0.96$), 0.031$ \\
\hline \multicolumn{4}{|l|}{ Sex: } \\
\hline Men & $270 / 630(43)$ & $1 \dagger$ & $1 \dagger$ \\
\hline Women & $150 / 745(20)$ & $\begin{array}{c}0.39(0.32 \text { to } 0.46), \\
<0.001\end{array}$ & 0.42 (0.35 to 0.50$),<0.001$ \\
\hline \multicolumn{4}{|l|}{ Ethnicity: } \\
\hline White & $370 / 1112(33)$ & $1 \dagger$ & $1 \dagger$ \\
\hline South Asian & $50 / 263(19)$ & $\begin{array}{c}0.50(0.32 \text { to } 0.78) \\
0.002\end{array}$ & 0.48 ( 0.34 to 0.67$),<0.001$ \\
\hline \multicolumn{4}{|l|}{ Deprivation (fifths): } \\
\hline Less deprived (1-4) & $360 / 1087(33)$ & $1 \dagger$ & $1 \dagger$ \\
\hline Most deprived (5) & $60 / 288(21)$ & $\begin{array}{c}0.58(0.34 \text { to } 0.995) \\
0.048\end{array}$ & 0.66 (0.40 to 1.08$), 0.099$ \\
\hline
\end{tabular}

of non-fatal acute coronary syndrome or death from coronary heart disease within five years of clinic visit according to whether or not patients underwent coronary angiography within three years of the index clinic attendance. To address the possibility of confounding by indication-those who did not undergo the procedure might have had too high a coronary risk - we adjusted for all other demographic variables, secondary prevention medication, and result of exercise ECG. The regression models were fitted for each demographic subgroup separately (for example, men separately), and the hazard ratios presented refer to the risk of an event related to not undergoing angiography. The final model of risk of a coronary event incorporated a propensity score for individuals that, in addition to the above variables, included diabetes, hypertension, hypercholesterolaemia, and duration and character of symptoms. The propensity score is the probability of receiving treatment for a patient with specific prognostic factors and is a scalar summary of all measured confounders. ${ }^{23} \mathrm{We}$ assessed differences in the event rates between subgroups with an interaction test. ${ }^{24}$

Patients with severe comorbid conditions might not have been referred for angiography, though they fulfilled the panels' criteria for appropriateness. To control for this possible confounding, in an additional analysis we excluded all patients with admissions for non-coronary conditions (all ICD chapters apart from I for circulatory disease, R00-03 for symptoms and signs involving the circulatory system, and R07.4 for unspecified chest pain) in the year after the index attendance.

\section{RESULTS}

Receipt of coronary angiography by appropriate patients Table 1 shows the characteristics of 1375 patien ts according to whether or not they underwent angiography. Overall, 69\% of patients deemed appropriate for angiography did not undergo this investigation. Table 2 shows hazard ratios by demographic groups for receipt of angiography by those deemed appropriate for this procedure after the index clinic visit. Multivariable analysis shows that people aged over 65, women, south Asian patients, and those in the most deprived population fifth were less likely to receive coronary angiography compared with those aged under 50, men, white patients, and those living in the less deprived fifths, respectively. The inequitable pattern of receipt was not explained by comorbidity

Table 3 | Risk of coronary event ( $n=230)$ within five years from index clinic attendance in 1375 patients deemed appropriate for angiography comparing patients who did not undergo angiography with those who did

\begin{tabular}{|c|c|c|c|c|c|}
\hline \multirow[b]{2}{*}{ Variable } & \multicolumn{2}{|c|}{ No of events/No of patients (\%) } & \multicolumn{3}{|c|}{ Hazard ratio $(95 \% \mathrm{Cl})$} \\
\hline & $\begin{array}{l}\text { Angiography not } \\
\text { received }\end{array}$ & Angiography received & Univariate & Multivariable* & $P$ value \\
\hline \multicolumn{6}{|l|}{ Age (years): } \\
\hline$\leq 49$ & 23/70 (33) & 6/42 (14) & 3.02 (1.79 to 5.10$)$ & 3.30 (1.70 to 6.43$)$ & $<0.001$ \\
\hline $50-64$ & 79/452 (17) & $25 / 217(12)$ & 1.52 (0.91 to 2.53$)$ & 1.90 (1.07 to 3.37$)$ & 0.028 \\
\hline$\geq 65$ & $81 / 433(17)$ & $16 / 161(10)$ & 1.83 (1.33 to 2.52$)$ & 2.23 (1.37 to 3.62$)$ & 0.001 \\
\hline \multicolumn{6}{|l|}{ Sex: } \\
\hline Men & $81 / 360(20)$ & $34 / 270(13)$ & 1.86 (1.12 to 3.09$)$ & 1.90 (1.12 to 3.22$)$ & 0.017 \\
\hline Women & 102/595 (16) & 13/150 (9) & 1.97 (1.24 to 3.14$)$ & 2.75 (1.52 to 5.00$)$ & 0.001 \\
\hline \multicolumn{6}{|l|}{ Ethnicity: } \\
\hline White & 142/742 (18) & $39 / 370(11)$ & 1.88 (1.42 to 2.49$)$ & 2.23 (1.46 to 3.39$)$ & $<0.001$ \\
\hline South Asian & 41/213 (18) & $8 / 50(16)$ & $1.22(0.65$ to 2.31$)$ & $1.52(0.68$ to 3.39$)$ & 0.307 \\
\hline \multicolumn{6}{|l|}{ Deprivation (fifths): } \\
\hline Less deprived $(1-4)$ & 135/727 (17) & $37 / 360(10)$ & $1.87(1.38$ to 2.53$)$ & 2.31 (1.55 to 3.43$)$ & $<0.001$ \\
\hline Most deprived (5) & $48 / 228(21)$ & $10 / 60(17)$ & $1.32(0.95$ to 1.84$)$ & $1.48(1.10$ to 2.00$)$ & 0.010 \\
\hline
\end{tabular}

*Each variable mutually adjusted for other variables (age, sex, ethnicity, deprivation) and for secondary prevention medication (aspirin, $\beta$ blockers, statins) and abnormal exercise ECG variable). 


\begin{tabular}{|c|c|c|c|c|c|}
\hline \multirow[b]{2}{*}{ Variable } & \multicolumn{2}{|c|}{ No of events/No of patients (\%) } & \multirow{2}{*}{\multicolumn{2}{|c|}{$\begin{array}{c}\text { Multivariable } \\
\text { hazard ratio }(95 \% \mathrm{Cl})\end{array}$}} & \multirow{3}{*}{$\begin{array}{c}\text { Multivariable } \\
\text { hazard ratio }(95 \% \mathrm{Cl})\end{array}$} \\
\hline & $\begin{array}{l}\text { Angiography } \\
\text { not received }\end{array}$ & $\begin{array}{l}\text { Angiography } \\
\text { received }\end{array}$ & & & \\
\hline \multicolumn{5}{|l|}{ Age (years): } & \\
\hline$\$ 49$ & $23 / 70(33)$ & 6/42 (14) & & & $3.30(1.70$ to 6.43$)$ \\
\hline $50-64$ & 79/452 (17) & 25/217 (12) & & $=$ & $1.90(1.07$ to 3.37$)$ \\
\hline$\geqslant 65$ & $81 / 433(17)$ & 16/161 (10) & & $\longrightarrow$ & 2.23 (1.37 to 3.62$)$ \\
\hline \multicolumn{6}{|l|}{ Sex: } \\
\hline Men & $81 / 360(20)$ & $34 / 270(13)$ & & $\longrightarrow$ & $1.90(1.12$ to 3.22$)$ \\
\hline Women & 102/595 (16) & $13 / 150(9)$ & & $\rightarrow$ & 2.75 (1.52 to 5.00$)$ \\
\hline \multicolumn{6}{|l|}{ Ethnicity: } \\
\hline White & 142/742 (18) & 39/370 (11) & & $\longrightarrow$ & 2.23 (1.46 to 3.39$)$ \\
\hline South Asian & 41/213 (18) & $8 / 50(16)$ & & & 1.52 (0.68 to 3.39$)$ \\
\hline \multicolumn{6}{|l|}{ Deprivation (fifths): } \\
\hline Less deprived (1-4) & $135 / 727(17)$ & $37 / 360(10)$ & & $\longrightarrow$ & 2.31 (1.55 to 3.43$)$ \\
\hline \multirow[t]{3}{*}{ Most deprived (5) } & 48/228 (21) & $10 / 60(17)$ & & $\rightarrow-$ & $1.48(1.10$ to 2.00$)$ \\
\hline & & & 0.4 & 3.0 & \\
\hline & & & $\begin{array}{l}\text { Reduced } \\
\text { risk }\end{array}$ & $\begin{array}{r}\text { Increased } \\
\text { risk }\end{array}$ & \\
\hline
\end{tabular}

Fig 2 | Forest plot of multivariable hazard ratios from table 3

in patients who did not receive angiography; it persisted when we excluded from the analysis the 252 patients with a non-coronary admission in the year after the index visit to the chest pain clinic. In an additional analysis, when patients were assumed to have more severe angina (Canadian Cardiac Society class III-IV) we found similar results: multiple adjusted hazards ratios 0.64 (0.35 to 1.17$)$ in 65 and older, 0.36 (0.30 to 0.44$)$ in women, 0.53 (0.37 to 0.76 ) in south Asians, and 0.64 (0.43 to 0.96$)$ in the most deprived fifth.

Coronary events by receipt of coronary angiogram in appropriate patients

For the whole cohort, prognosis of patients deemed appropriate for coronary angiography and who received the procedure was better than those who did not (hazards ratio $1.71,95 \%$ confidence interval 1.24 to 2.34). Table 3 shows univariate and multivariable hazard ratios (fig 2) for a coronary event over five years of follow-up according to whether or not patients had undergone angiography in the first three years. Hazard ratios for a coronary event were $>1$ for all demographic groups, with a significantly increased risk for younger people, older people, men, women, white people, and the less deprived fifths. Tests for interaction showed no significant difference between hazard ratios for the three age groups $(\mathrm{P}=0.203$ and 0.223$)$, between men and women $(\mathrm{P}=0.493)$, between white people and south Asians $(\mathrm{P}=0.426)$, and between the most deprived and less deprived population fifths $(\mathrm{P}=0.077)$. The worse prognosis for appropriate patients who did not undergo angiography persisted when we excluded those with non-coronary admissions in the year after index clinic attendance (table 4).

\section{DISCUSSION}

Despite the strong emphasis on fairness of access to cardiac investigation in the UK national service framework for coronary heart disease published in 2000, we found that older people, women, and south Asians who were deemed appropriate for coronary angiography were significantly less likely to receive the investigation. Deaths from coronary heart disease and admissions for unstable angina and myocardial infarction were more common in patients deemed appropriate for coronary angiography but who had not received it. The prognostic validity of appropriateness ratings for coronary angiography was apparent in all demographic subgroups, with hazard ratios for a coronary event $>1$ for appropriate patients who did not undergo angiography, although the difference was not significant for south Asians.

Table 4 Risk of coronary event ( $n=230$ ) within five years from index clinic attendance in 1375 patients deemed appropriate for angiography comparing patients who did not undergo angiography with those who did, excluding patients with non-coronary hospital admissions within year of index visit

\begin{tabular}{|c|c|c|c|c|c|}
\hline \multirow[b]{2}{*}{ Variable } & \multicolumn{2}{|c|}{ No of events/No of patients (\%) } & \multicolumn{2}{|c|}{ Hazard ratio $(95 \% \mathrm{Cl})$} & \multirow[b]{2}{*}{$P$ value } \\
\hline & $\begin{array}{l}\text { Angiography not } \\
\text { received }\end{array}$ & Angiography received & Univariate & Multivariable* & \\
\hline \multicolumn{6}{|l|}{ Age (years): } \\
\hline$\leq 49$ & 23/70 (33) & 6/42 (14) & $3.02(1.79$ to 5.10$)$ & 3.90 (1.70 to 8.93$)$ & 0.001 \\
\hline $50-64$ & $79 / 452(17)$ & $25 / 217$ (12) & $1.52(0.91$ to 2.53$)$ & $1.66(0.98$ to 2.80$)$ & 0.057 \\
\hline$\geq 65$ & $81 / 433(17)$ & 16/161 (10) & 1.83 (1.33 to 2.52$)$ & $2.50(1.40$ to 4.45$)$ & 0.002 \\
\hline \multicolumn{6}{|l|}{ Sex: } \\
\hline Men & $81 / 360(20)$ & $34 / 270(13)$ & $1.86(1.12,3.09)$ & 2.03 (1.26 to 3.27$)$ & 0.003 \\
\hline Women & 102/595 (16) & 13/150 (9) & $1.97(1.24$ to 3.14$)$ & $2.37(1.34$ to 4.20$)$ & 0.003 \\
\hline \multicolumn{6}{|l|}{ Ethnicity: } \\
\hline White & 142/742 (18) & $39 / 370(11)$ & $1.88(1.42$ to 2.49$)$ & 2.18 (1.55 to 3.08$)$ & $<0.001$ \\
\hline South Asian & 41/213 (18) & $8 / 50(16)$ & $1.22(0.65$ to 2.31$)$ & 1.89 (0.59 to 6.03$)$ & 0.285 \\
\hline \multicolumn{6}{|l|}{ Deprivation (fifths): } \\
\hline Less deprived (1-4) & 135/727 (17) & $37 / 360(10)$ & $1.87(1.38$ to 2.53$)$ & 2.55 (1.90 to 3.42 ) & $<0.001$ \\
\hline Most deprived (5) & $48 /-228(21)$ & $10 / 60(17)$ & $1.32(0.95$ to 1.84$)$ & 1.24 (1.02 to 1.50$)$ & 0.030 \\
\hline
\end{tabular}

*Each variable mutually adjusted for other variables (age, sex, ethnicity, deprivation) and for secondary prevention medication (aspirin, $\beta$ blockers, statins) and abnormal exercise ECG variable). 


\section{WHAT IS ALREADY KNOWN ON THIS TOPIC}

Potential inequities in the management of cardiovascular disease might have consequences in terms of prognosis

Access to cardiac investigation early in the course of chronic coronary disease might be inequitable

Few studies on inequitable use of investigations consider appropriateness of the procedures

\section{WHAT THIS STUDY ADDS}

In patients with angina of recent onset deemed appropriate for angiography, older patients, women, south Asians, and those living in the most deprived wards were less likely to undergo this procedure

Older patients, women, south Asians, and those from the most deprived areas deemed appropriate for coronary angiography who did not receive it had a higher rate of coronary events than those who did

\section{Strengths and weaknesses}

The key contributions of this study are the robust measurement of inequity in use of coronary angiography, taking into account the appropriateness of the investigation and comorbidity; and demonstration of the detrimental effect of this inequity on prognosis. This has important implications for clinical decision making in the first consultation patients with stable chest pain have with cardiac specialists. Our findings are probably applicable to patients attending chest pain clinics throughout the UK as the risk profile and prognosis of the whole cohort is comparable with that in other studies in chest pain clinics. ${ }^{2526}$ Appropriateness ratings for coronary angiography can inform better decisions by clinicians. We tested specific ratings against conventional guidelines in a web based trial of investigative decisions for patients with chest pain and found that the ratings significantly improved the ordering of exercise electrocardiography and coronary angiography. ${ }^{22}$

Our analysis of referral and coronary outcomes from rapid access chest pain clinics was multicentred and based on a clinical population with uniformly collected data at the patient level, including ethnicity. We used independent and reliable ${ }^{27}$ measures of coronary events and deaths from National Statistics and the NHS-wide clearing system. These clinics are ideal settings for investigating access to angiography and the outcomes of patients with incident angina. ${ }^{28} \mathrm{~A}$ major strength of the study is the precise attribution of need for coronary angiography using appropriateness ratings. The sample size allowed robust comparison between demographic and clinical subgroups in terms of receipt or non-receipt of angiography and, for most subgroup comparisons, of coronary events. Other strengths include the use of data at the patient level on non-coronary admissions to test the effect of potential indication bias.

A potential limitation in this study is the broad classification of ethnicity and its source in the labelling of patients by clinicians who entered the information on the database. The validity of these categories, whatever their source, depends on the research question. ${ }^{29}$ We were able to answer questions about inequity relating to a broad category of ethnicity that maps on to census classifications. It is justified to pose these questions because previous research in the UK suggests inequitable access to some cardiac services using broad ethnicity categories ${ }^{30}$ and also because discrimination by clinicians against ethnically heterogeneous minority groups might be an explanation for inequity. ${ }^{31}$ Furthermore, in an analysis of 33 patients in chest pain clinics, Zaman (J Zamman, personal communication) found a high agreement ( $\kappa$ of 0.77 ) between ethnic group according to the patients and the cardiologist.

A second limitation stems from the use of a deprivation measure, the Townsend score, that is based on ward rather than individual level socioeconomic status, and therefore the analysis is less precise and prone to the ecological fallacy: ascription of average deprivation across a ward to an individual who lives in that ward. On the other hand, Britton and colleagues ${ }^{6}$ used individual level data and found no inequity by socioeconomic status or ethnicity.

Finally, we did not assess potential inequities related to age, ethnicity, or deprivation in referral of patients with chest pain from primary care into specialist services. ${ }^{32}$

\section{Relevance of findings}

Why do these inequities in use of coronary angiography arise? They could reflect differential referral of appropriate patients ${ }^{33}$ although in a previous study differential referral for treatment proved not to be the cause of differences in rates of coronary revascularisation. ${ }^{14}$ Qualitative research in chest pain clinics did not show any marked differences in clinical assessment by age or sex, although this did differ between south Asians and whites, largely because of language barriers. ${ }^{34}$ Some variation in use of coronary angiography might result from patients' choices not to undergo the procedure, which could vary systematically by demographic group..$^{35}$ There is a role for further qualitative research to elucidate why patients who are deemed appropriate for coronary angiography do not receive it.

Over and above inequalities between groups in use of angiography, it is striking that there is underuse across our whole cohort, with less than a third of appropriate patients receiving it. This is consistent with the findings of the Euro Heart study from outpatient cardiology services in 34 countries. ${ }^{12}$ We think it unlikely that the appropriateness ratings for coronary angiography ascribed to the cohort are invalid, thus overestimating the proportion of patients who should have the procedure. The association between nonreceipt of angiography with increased coronary events is external validation of the ratings and this association extends to those patients of uncertain appropriateness with a hazard ratio of 1.97 (1.17 to 3.34). 


\section{Conclusion}

Our findings and those of previous studies ${ }^{13}$ should inform policy to deal with sources of inequity in the provision of cardiac services. The prospective validity of appropriateness ratings for cardiac investigation developed with the Rand/UCLA method means that they are a robust basis for guidance to clinicians in rapid access chest pain clinics. Application of that guidance to decision making about individual patients might help to address inequitable access to angiography for some groups of patients with recent onset chest pain. The potential of appropriate ratings for specific patients to improve investigative decisions for patients with chest pain ${ }^{22}$ now needs to be tested in real clinical settings. Appropriateness ratings incorporated into decision support systems might have a wider application for investigative and treatment decisions in other clinical settings.

In memory of Sarah Cotter (1949-2004), who worked on an earlier version of this analysis.

Contributors: All authors contributed to the design of this study. NS, NW, C), and RC carried out the analyses. GF wrote the first draft of the paper and is guarantor, and all authors contributed to revisions.

Funding: NHS service delivery and organisation research and development programme.

Competing interests: None declared.

Ethical approval: Trent multicentre research ethics committee and all local research ethics committees.

Provenance and peer review: Not commissioned; externally peer reviewed.

1 Department of Health. The new NHS-modern and dependable. London: Department of Health, 1997. www.archive.officialdocuments.co.uk/document/doh/newnhs/newnhs.htm.

2 MacLeod MC, Finlayson AR, Pell JP, Findlay IN. Geographic, demographic, and socioeconomic variations in the investigation and management of coronary heart disease in Scotland. Heart 1999;81:252-6.

3 Bond M, Bowling A, McKee D, Kennelly M, Banning AP, Dudley N, et al. Does ageism affect the management of ischaemic heart disease? J Health Serv Res Policy 2003;8:40-7.

4 Morris RW, Whincup PH, Papacosta O, Walker M, Thomson A Inequalities in coronary revascularisation during the 1990s: evidence from the British regional heart study. Heart 2005;91:635-40.

5 Jones M, Ramsay J, Feder G, Crook AM, Hemingway H. Influence of practices' ethnicity and deprivation on access to angiography: an ecological study. Br J Gen Pract 2004; 54:423-8.

6 Britton A, Shipley M, Marmot M, Hemingway H. Does access to cardiac investigation and treatment contribute to social and ethnic differences in coronary heart disease? Whitehall II prospective cohort study. BMJ 2004;329:318.

7 Murphy NF, Simpson CR, Macintyre K, McAlister FA, Chalmers J, McMurray JJ. Prevalence, incidence, primary care burden and medical treatment of angina in Scotland: age, sex and socioeconomic disparities: a population-based study. Heart 2006;92:1047-54.

8 Hemingway H, McCallum A, Shipley M, Manderbacka K, Martikainen P, Keskimäki I. Incidence and prognostic implications of stable angina pectoris among women and men. JAMA 2006;295:1404-11.

9 Epstein AM, Weissman JS, Schneider EC, Gatsonis C, Leape LL, Piana RN. Race and gender disparities in rates of cardiac revascularization: do they reflect appropriate use of procedures or problems in quality of care? Med Care 2003;41:1240-55.

10 Alter DA, Naylor CD, Austin P, Tu JV. Effects of socioeconomic status on access to invasive cardiac procedures and on mortality after acute myocardial infarction. N Engl J Med 1999;341:1359-67.

11 Lurie N. Health disparities-less talk, more action. N Engl J Med 2005;353:727-9.

12 Daly C, Clemens F, Lopez Sendon JL, Tavazzi L, Boersma E, Danchin N, et al. Gender differences in the management and clinical outcome of stable angina. Circulation 2006;113:490-8.
13 Chen J, Rathore SS, Radford MJ, Wang Y, Krumholz HM. Racial differences in the use of cardiac catheterization after acute myocardial infarction. N Engl J Med 2001;344:1443-9.

14 Feder G, Crook AM, Magee P, Banerjee S, Timmis AD, Hemingway H. Ethnic differences in invasive management of coronary disease: prospective cohort study of patients undergoing angiography. $B M$ J 2002;324:511-6.

15 Rathore SS, Wang Y, Radford MJ, Ordin DL, Krumholz HM. Sex differences in cardiac catheterization after acute myocardial infarction: the role of procedure appropriateness. Ann Intern Med 2002;137:487-93.

16 Hemingway H, Crook AM, Feder G, Banerjee S, Dawson JR, Magee P, et al. Underuse of coronary revascularization procedures in patients considered appropriate candidates for revascularization. $N$ Engl Med 2001;344:645-54.

17 Sekhri N, Feder GS, Junghans C, Hemingway H, Timmis AD. Rapidaccess chest pain clinics and the traditional cardiology out-patient clinic. QJM 2006;99:135-41.

18 Ray S, Archbold RA, Preston S, Ranjadayalan K, Suliman A, Timmis AD. Computer-generated correspondence for patients attending an openaccess chest pain clinic. J R Coll Physicians Lond 1998;32:420-1.

19 Harding S, Rosato M, Teyhan A. Trends for coronary heart disease and stroke mortality among migrants in England and Wales, 1979-2003: slow declines notable for some groups. Heart 2008;94:463-70.

20 Townsend P. Deprivation. J Soc Policy 1987;16:125-46.

21 Brook RH, Chassin MR, Fink A, Solomon DH, Kosecoff J, Park RE. A method for the detailed assessment of the appropriateness of medical technologies. Int J Technol Assess Health Care 1986;2:53-63.

22 Junghans C, Feder G, Timmis AD, Eldridge S, Sekhri N, Black N, et al. Effect of patient-specific ratings vs conventional guidelines on investigation decisions in angina: appropriateness of referral and investigation in angina (ARIA) trial. Arch Intern Med 2007;167:195-202

23 Stukel TA, Fisher ES, Wennberg DE, Alter DA, Gottlieb DJ, Vermeulen MJ. Analysis of observational studies in the presence of treatment selection bias: effects of invasive cardiac management on AMI survival using propensity score and instrumental variable methods. JAMA 2007;297:278-85.

24 Altman DG, Bland JM. Interaction revisited: the difference between two estimates. BMJ 2003;326:219.

25 Tenkorang JN, Fox KF, Collier TJ, Wood DA. A rapid access cardiology service for chest pain, heart failure and arrhythmias accurately diagnoses cardiac disease and identifies patients at high risk: a prospective cohort study. Heart 2006;92:1084-90.

26 Taylor GL, Murphy NF, Berry C, Christie J, Finlayson A, Macintyre K, et al. Long-term outcome of low-risk patients attending a rapid-assessment chest pain clinic. Heart 2007 Oct 4 [Epub ahead of print].

27 West of Scotland Coronary Prevention Study Group. Computerised record linkage: compared with traditional patient follow-up methods in clinical trials and illustrated in a prospective epidemiological study. J Clin Epidemiol 1995;48:1441-52.

28 Sekhri N, Feder GS, Junghans C, Hemingway H, Timmis AD. How effective are rapid access chest pain clinics? Prognosis of incident angina and non-cardiac chest pain in 8762 consecutive patients. Heart 2007;93:458-63.

29 Bhopal R, Donaldson L. White, European, Western, Caucasian, or what? Inappropriate labeling in research on race, ethnicity, and health. Am J Public Health 1998;88:1303-7.

30 Institute of Community Health Sciences Research Group. Systematic review of access to and uptake of health services by ethnic minority groups: cardiovascular disease and mental health. London: NHS Executive London Research and Development.

2001. www.ichs.qmul.ac.uk/research/gppc/Download\%20Report/ ethnicity_accessreview.pdf.

31 Bowling A, Bond M, McKee D, McClay M, Banning AP, Dudley N, et al. Equity in access to exercise tolerance testing, coronary angiography, and coronary artery bypass grafting by age, sex and clinical indications. Heart 2001;85:680-6.

32 Hippisley-Cox J, Pringle M. Inequalities in access to coronary angiography and revascularisation: the association of deprivation and location of primary care services. BrJ Gen Pract 2000;50:449-54.

33 Redberg RF. Gender, race, and cardiac care: why the differences? J Am Coll Cardiol 2005;46:1852-4.

34 Somerville C, Featherstone K, Hemingway H, Timmis A, Feder GS. Performing stable angina pectoris: an ethnographic study. Soc Sci Med 2008;66:1497-508.

35 Heidenreich PA, Shlipak MG, Geppert J, McClellan M. Racial and sex differences in refusal of coronary angiography. Am J Med 2002;113:200-7.

Accepted: 26 March 2008 